\title{
Novel reaction products from simple organic reactions: Delineation of reaction pathways
}

\author{
Subhash C Jain`, Sangeeta Talwar, Sunita Bhagat, Vivek K Rajwanshi, Ravindra Kumar \\ and B Ravindra Babu \\ Department of Chemistry, University of Delhi, Delhi-110 007 (India).
}

\begin{abstract}
In continuation of our interest in the synthesis of biologically active, natural and synthetic compounds, we have come across some surprises even with simple reactions like alkylation, condensation and rearrangement, which have resulted in the formation of some unusual novel products. Structures of these were assigned on the basis of their detailed spectral analysis and also confirmed in a few cases by X-ray crystal studies. Mechanistic aspects of the plausible routes of their formation have also been presented.
\end{abstract}

\section{NOVEL PRODUCTS OF FRIES REARRANGEMENT}

The Fries rearrangement is an exceedingly convenient and general method for the preparation of hydroxyketones from phenol esters and the formation of product(s) depends upon the reaction conditions used (ref. 1). It finds wide application in synthetic organic chemistry since both the acid and the phenol from which the phenol esters are derived can be varied. Metal promoted (ref. 2), anionic (ref. 3) and Photo Fries rearrangements (ref. 4), because of their specific advantages are gaining more importance these days for the regiospecific preparation of varieties of new compounds. Beside these, Fries reaction has been also used for the preparation of various synthons, required for the synthesis of number of polycyclic compounds like benzofurans, steroids, coumarins and isocoumarins.

We, in continuation of our interest in the field of natural product synthesis, envisaged the preparation of synthon 1, required for the synthesis of Candirone [5-hydroxy-2-(4-hydroxyphenyl)-3,6,8-trimethoxy-4H-1benzopyran-4-one] (2), isolated by Parmar et al (ref. 5), from the seeds of Tephrosia candida. Interest in the synthesis of 2 was due to the rare oxygenation pattern (structure revised recently; ref. 6) and also because it was isolated from the extract that has been earlier found to possess strong insecticidal activity (ref. 7).Sarin et al (ref. 8) have also observed the activity against human epidermoid carcinoma of the nasopharynx in tissue culture $(9 \mathrm{~KB})$ in $50 \%$ ethanolic extract of the plant.<smiles>COCC(=O)c1c(O)c(Br)cc(Br)c1O</smiles>

$1 \mathrm{R}=\mathrm{CH}_{3}, \mathrm{R}_{1}=\mathrm{OCH}_{3}$ $3 \mathbf{R}=\mathbf{R}_{\mathbf{1}}=\mathbf{H}$<smiles>COc1cc(OC)c2c(O)c(-c3ccc(O)cc3)oc(=O)c2c1O</smiles>

2<smiles>Cc1cc(=O)oc2c(Br)c(O)ccc12</smiles>

$4 \mathrm{R}=\mathrm{COCH}_{2} \mathrm{OCH}_{3}, \mathrm{R}_{1}=\mathrm{H}$ $5 \mathrm{R}=\mathrm{H}, \mathrm{R}_{1}=\mathrm{COCH}_{2} \mathrm{OCH}_{3}$<smiles></smiles>

6<smiles>Cc1cc(=O)oc2cc(Cc3c(O)ccc4c(C)cc(=O)oc34)c(O)cc12</smiles>

The synthesis of the desired synthon, 2-hydroxy- $\omega, 3,5,6$-tetramethoxy acetophenone (1) was planned in number of steps starting from 2,6-dihydroxy- $\omega$-methoxy acetophenone (3) which could be obtained from 7-0methoxyacetyl-4-methyl-2H-1-benzopyran-2-one (4) via Fries rearrangement followed by alkaline hydrolysis of the resulting 8-acyl derivative (5). 4 was obtained from 7-hydroxy-4-methyl-2H-1-benzopyran-2-one by acylation with methoxyacetyl chloride in presence of pyridine under dry conditions. 7-O-Methoxyacetyl-4methyl-2H-1-benzopyran-2-one,when subjected to a Lewis acid mediated Fries rearrangement under dry condition, gave surprisingly two new isomeric biscoumarins $A_{1}$ and $A_{2}$ instead of the expected product 7hydroxy-8-methoxyacetyl-4-methyl-2H-1-benzopyran-2-one or 7-hydroxy-6-methoxyacetyl-4-methyl-2H-1benzopyran-2-one. These new biscoumarins have been characterized as 8,8 '-methylene bis-(7-hydroxy-4methyl-2H-1-benzopyran-2-one, (6) and 6,8'-methylene bis-(7-hydroxy-4-methyl-2H-1-benzopyran-2-one, (7) respectively on the basis of detailed spectral studies. 
<smiles></smiles>

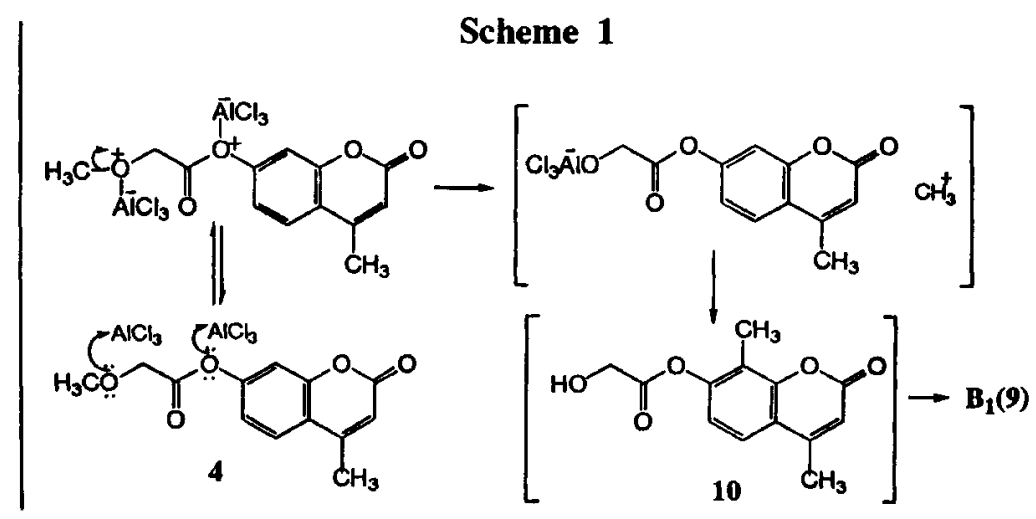

Since some of the naturally occurring as well as synthetically known biscoumarins have been reported to possess a wide range of activities such as antibacterial (ref. 9), antiasthmatic (ref. 10), anthelmintic (ref. 11), anticancer (ref. 12) and insecticidal (ref. 13), so we were tempted to repeat the above reaction in the solution phase using acetylene tetrachloride as the solvent in order to get either new products or the desired rearranged product 5 . To our utmost surprise, we obtained again two products $B_{1}$ and $B_{2}$, which were not the expected products and were also different from the earlier isolated biscoumarins. The major product, $\mathrm{B}_{2}$ turned out to be a novel compound and was characterized as 8,3'-methylene (7-hydroxy-4-methyl-2H-1benzopyran-2-one) [4"-methylpyran-2"-one (5', 6': 6", 5")-2H-1-benzopyran-2-one] (8), on the basis of detailed spectral studies such as ${ }^{1} \mathrm{H}$ NMR, ${ }^{13} \mathrm{C}$ NMR, 2D NMR, EIMS and CIMS. Since the structure proposed for $B_{2}$ was novel and assigned strictly on the basis of spectral studies, we have confirmed it by $X$-ray studies on its acetate also. The minor reaction product $B_{1}$ was found to be a simple coumarin derivative and characterized as 4,8-dimethyl-7-oxalyoxy-2H-1-benzopyran-2-one (9). This assignment was further confirmed by its synthesis via an alternate route. Plausible routes for the formation of $B_{1}$ and $B_{2}$ are depicted in Scheme 1 and 2 , respectively.

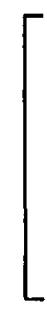<smiles>COc1ccc2c(C)cc(=O)oc2c1C</smiles>

10

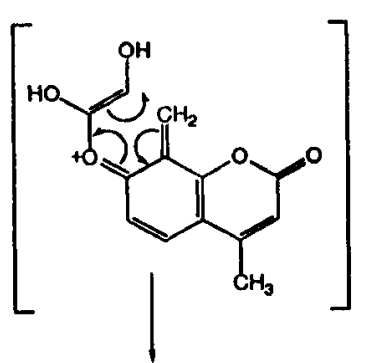<smiles>Cc1cc(=O)oc2c3c(ccc12)CCCC3</smiles>

Scheme 2<smiles>Cc1c(O)ccc2c1O[C@H](O)C[C@@H]2C</smiles>

11 


\section{NOVEL SPIRO COMPOUNDS OF CONDENSATION REACTION}

The vogue of constructing complex biologically active molecules by molecular modification has been of enormous interest in recent years. The synthesis requires precise control of stereochemistry and the rational and mechanistically based design of process. However, inspite of controlled conditions, such type of synthesis sometimes results in unusual products, the study of which gives insight into the formation of new carboncarbon bond.

Among the various heterocyclic systems, spiro indoles are of great importance in view of their varied biological activities (ref. 14-16) : Spiro [cyclohexane-1,3'-[3H] indole] and spiro [cyclopentane-1,3'-[3H]indole] are used as analgesics (ref. 17), fungicides (ref. 18), antidepressants (ref. 19) and anti inflammatory agents (ref. 20), spiro [indole-pyrrolidines] exhibit local anaesthetic activity (ref. 21) and binding affinity to glycine receptor (ref. 22), spiro [3H-indole-3,4'-[4H] pyran]-2[1H]-ones are used as anti inflammatory agents (ref. 23) and spiro [3H-indole-3,3'-pyrazolin]-2-ones as antiphologistics and blood platelet aggregators (ref. 24,25). These broad spectrum of biological activities of spiro-indole heterocyclic systems prompted us to make some more similar novel spiro compounds containing two different moieties by using simple reactions and to examine their biological activities.

For this purpose, indole-2,3-dione (isatin) and 4-hydroxy coumarin have been choosen as two moieties because of their biological importance and also because they contain structural features which could be exploited to couple them together using simple condensation reaction. Such reaction when carried out in dry ethanol under refluxing conditions gave mainly an unusual product which was characterized as 3,4 'spiro [ $3 \mathrm{H}$ 2-oxo-indol-(4'H)] [pyrano (4",3"-b) (4",3"-e) bis-2H-1-benzopyran] (12) along with a small amount of dicoumarol ${ }^{*} 13$. However, in the presence of either acetic acid or diethylamine, the expected condensation product 14 was obtained, which on subsequent cyclization afforded 12. In order to compare the biological activities of various spiro indoles, analogs of 12 have been made by repeating the reaction with $\mathrm{N}$-methyl and 5-fluoro derivatives of indole-2,3-dione in all the three media.

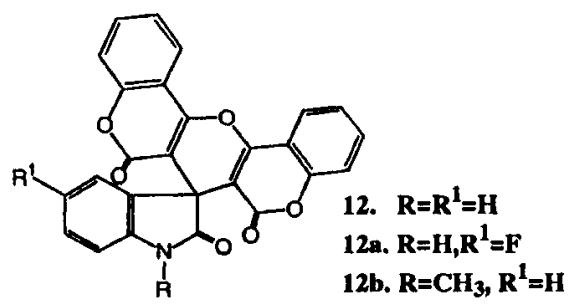

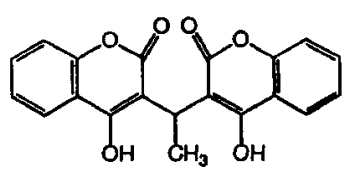

13

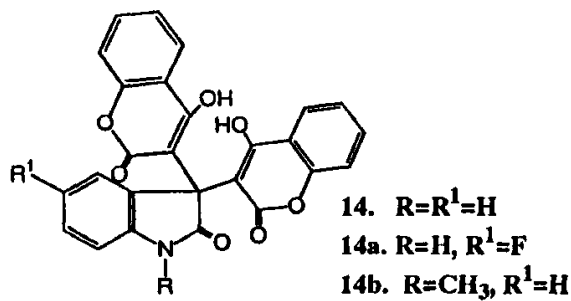

Further, we attempted the synthesis of an unknown tricyclic indole-1,2-oxazine system 16, starting from 3aroyl methylene indol-2-one (15) via its oxime as an intermediate. However, 15 when treated with hydroxylamine hydrochloride in absolute ethanol in the presence of pyridine gave mainly an unusual compound identified as spiro [3H-indole-3,5'-isoxazolin]-2-one. (17) alongwith a small amount of the expected oxime 18. It may be mentioned here that Kobayashi et al. have prepared similar compounds in poor yield by a cumbersome method and reported them as central nervous drugs (ref. 26).

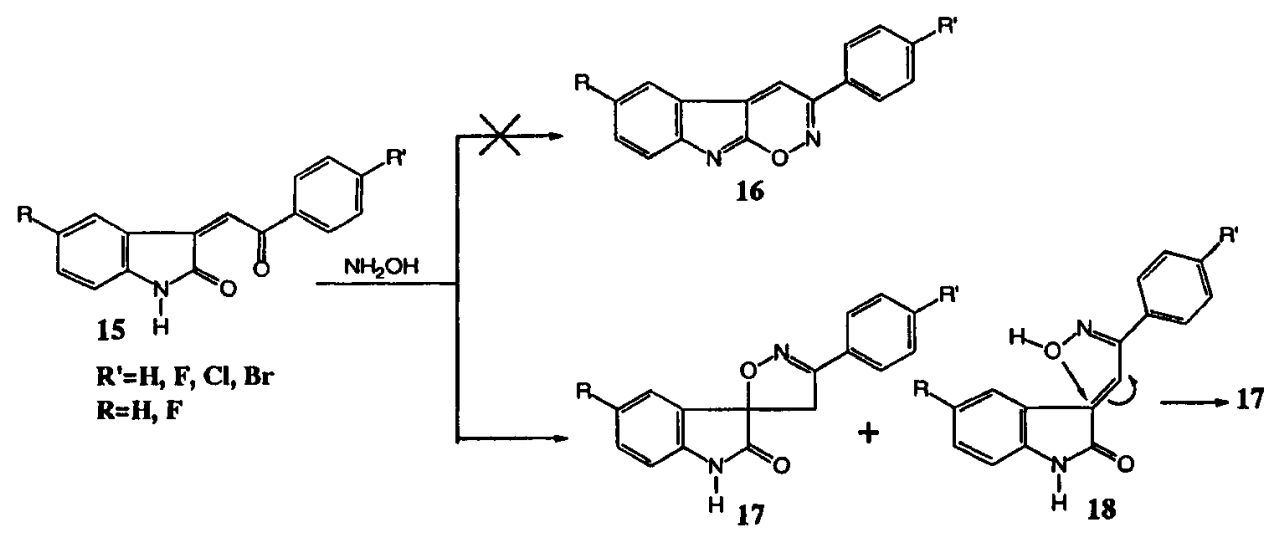

13 might have been formed because of the presence of small amount of acetaldehyde impurity in the solvent used for the reaction. 


\section{NOVEL PRODUCTS OF ALKYLATION REACTION}

In our efforts to synthesise new heterocyclic systems of biological importance, we also made an attempt to synthesise new imidazolo indole system 19. The initial step required alkylation of indol-2,3-dione with phenacyl bromide. When the reaction was carried out in the presence of dry $\mathrm{K}_{2} \mathrm{CO}_{3}$, using acetone as solvent under refluxing conditions, two products 20 and $\mathbf{2 1}$, different from the desired one, were obtained. Compound 20 was formed as a result of simultaneous $\mathrm{N}$-alkylation and base-catalysed condensation involving the free carbonyl at $\mathrm{C}-3$ position and the carbanion formed from the solvent acetone, while 21 resulted from the $\mathrm{N}$ alkylation followed by condensation at the benzoyl carbonyl. Since acetone had reacted in the above reaction, so we repeated the alkylation reaction using THF as the solvent. But this time also, to our utmost surprise, we obtained another new product 22 in substantial amount, which probably has resulted from the initial Nalkylation followed by nucleophilic displacement of bromine from another phenacyl bromide molecule by the enolate ion, formed as a result of the presence of $\mathrm{K}_{2} \mathrm{CO}_{3}$ in the reaction mixture.

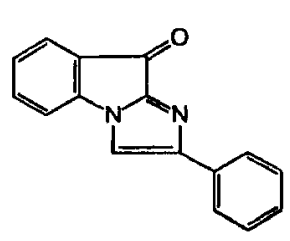

19

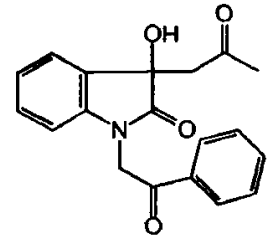

20

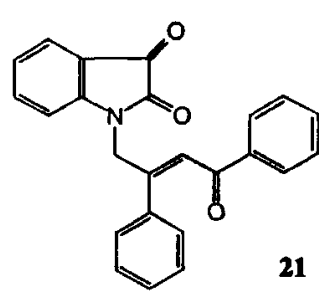

21

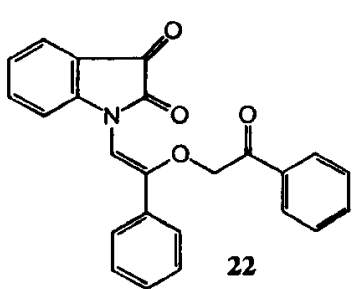

22

\section{CONCLUSION}

In conclusion, it can be stated that though the development of a new synthetic methodology requires mechanistically based design of new regents and processes, yet one comes across many surprises with respect to the product(s) obtained from organic reactions. We have also made similar observations in our laboratory and obtained unusual products from simple reactions like alkylation, condensation and rearrangement. The study of these products often gives insight into the new carbon - carbon bond formation that helps in predicting the new reaction path ways. Besides, generality of the reaction can be proved by varying the substrate and the substituents present therein and finally it could be used for the synthesis of new organic compounds.

Acknowledgement We thank Dr W Errington (University of Warwick, UK) for X-ray studies, University Grants Commission, New Delhi and Council of Scientific and Industrial Research, New Delhi for financial assistance.

\section{References}

1. R. Martin, Org. Prep. Proceed. Int., 24, 369 (1992).

2. J.A. Miller, J.Org. Chem., 52, 323 (1987).

3. W. Wang and V. Snieckus, J. Org. Chem., 57, 424 (1992).

4. D. Bellus, Advan. Photochem, 8, 109 (1971).

5. V.S. Parmar, R. Jain, O. Simonsen and P.M. Boll, Tetrahedron, 43, 4241 (1987).

6. T. Houie, Y. Kawamaru, T. Kobayashi and K. Yamashita, Phytochemistry, 37, 1189 (1994).

7. The wealth of India, Raw materiais, CSIR publication, New Delhi X, 152 (1976).

8. J.P.S. Sarin, S. Singh, H.S. Garg, N.M. Khanna and M.M. Dhar, Phytochemistry, 15, 232 (1976).

9. R.C. Boguslaski, J. Chem. Eng. Data, 19, 103 (1974).

10. U. Suminori and S. Yoshinari, Japan Kokai, 11, 882 (1974).

11. J. Sulko and Farmaco, Ed. Sci, 26, 146 (1971).

12. D. Frank, J. Med. Pharm. Chem., 5, 627 (1962).

13. Dow. Chem. Co., Ao1n, CO7d, 4PP, U.S. Patent, 3, 509, 177.

14. K.C. Joshi, R. Jain and P. Chand, Heterocycles, 23, 957 (1985).

15. F.D. Popp, J. Heterocycl. Chem., 9, 1399 (1972).

16. H. Otomasu and S. Ohmiya, Japan Kokai, 75, 140441 (1975); Chem. Abstr., 85, 32991(1976).

17. M. Wolf and A.A. Mascitti, U.S. Patent, 3, 395, 156 (1968); Chem. Abstr., 69, 96504 (1968).

18. Rohm and Hass Co., Brit. Patent, 913, 937 (1962); Chem. Abstr., 59, 577 (1963).

19. N.A. Johnsson, L. Mikiver \& P. Moses, Ger. Patent, 2, 245, 159 (1973); Chem. Abstr., 78, 159460 (1973).

20. G. Winters and N. Di. Mola, Ger. Patent, 2442, 667, (1975); Chem. Abstr., 83, 28096 (1975).

21. M.J. Kornet and A.P. Thio, J. Med. Chem., 19, 892 (1976).

22. F.M. Hershenson, K.A. Prodan and R.L. Kochman, J. Med. Chem., 22, 1448(1977).

23. G. Kobayashi and Y. Matsuda, Japan Patent, 7025, 894 (1970); Chem Abstr., 74, 3529 (1971).

24. G. Kobayashi and Y. Matsuda, Japan Patent, 68, 03, 385 (1968); Chem. Abstr., 69, 96716 (1968).

25. K. Kikugawa and M. Ichino, Chem. Pharm. Bull., 21, 1151 (1973).

26. G. Kobayashi and Y. Matsuda, Japan Patent, 70, 40, 894 (1970); Chem Abstr., 75, 20386 (1971). 